7. Reprod. Fert. (1969) 20, 165-169

\title{
PULSE ATTENUATION AND COUNTERCURRENT HEAT EXCHANGE IN THE INTERNAL SPERMATIC ARTERY OF SOME AUSTRALIAN MARSUPIALS
}

\author{
B. P. SETCHELL ANd G. M. H. WAITES \\ CSIRO, Division of Animal Physiology, The Ian Clunies Ross Animal Research \\ Laboratory, Prospect, N.S.W., Australia, and Department of Physiology, \\ University of Sydney, Sydney, N.S.W., Australia
}

(Received 21st April 1969)

The unusual complexity of the testicular blood vessels of eutherian mammals has been shown to have haemodynamic and thermoregulatory significance. The pulse wave of pressure passing down the long, coiled internal spermatic artery of the ram (Waites \& Moule, 1960), dog (Blombery, Gow \& Waites, unpublished observations) and rat (Setchell, 1969) is attenuated to a small oscillation, but mean blood pressure is only marginally reduced. A similar pressure-damping action was described for the carotid rete mirabile of the dolphin (Nagel, Morgane, McFarland \& Galliano, 1968). There is also plentiful evidence for countercurrent heat exchange between neighbouring arteries and veins (see Waites, 1969). As the spermatic veins closely surround the internal spermatic artery, Harrison \& Weiner (1949) proposed that heat exchange was occurring between the counterflowing blood streams. This was confirmed by measuring the thermal gradients in the testicular circulation of dogs (Dahl \& Herrick, 1959) and rams (Waites \& Moule, 1961).

The internal spermatic artery of most marsupials divides into many parallel branches which intermingle in the spermatic cord with a similar number of parallel veins (Harrison, 1948, 1949, 1951; Barnett \& Brazenor, 1958). One might expect that this different way of increasing vascular surface area, by branching rather than elongation, would have similar haemodynamic and thermal consequences, but experiments to examine this have apparently not been performed.

Six adult tammar wallabies (Macropus eugenii Desmarest) weighing between 5.4 and $9 \mathrm{~kg}$, and two adult red kangaroos (Megaleia rufa Desmarest), weighing 36 and $42 \mathrm{~kg}$, were anaesthetized with pentobarbitone sodium. Rectal temperature, recorded with a thermocouple, was maintained with an electric blanket at the values recorded immediately after anaesthesia. The testes were exposed and copper constantan thermocouples (45 S.W.G. mounted in the tips of 25 S.W.G. hypodermic needles) were immediately inserted into the testis, and into a testicular vein and a testicular artery on the surface of one testis. Two to four arteries run along the epididymal margin and a similar number of veins along the free margin (Setchell, 1969). It was thus possible to insert the needle into one vessel and push it as far as a junction with another so that blood was flowing past the site of measurement. The arterial thermocouple was within 
2 to $3 \mathrm{~mm}$ of where the artery reached the testis so it would be unlikely that the temperature of the arterial blood would be significantly changed by loss of heat directly to the testis. The testes were covered with cotton gauze and temperatures recorded for at least $10 \mathrm{~min}$. During this time, a 24 S.W.G. needle connected to polyethylene tubing ( $0.5 \mathrm{~mm}$ I.D., $0.8 \mathrm{~mm}$ O.D., Dural Plastics, Dural, N.S.W., Australia) filled with saline was inserted into a femoral artery and arterial blood pressure recorded with a strain gauge pressure transducer (Statham, P23Db, Hato Rey, Puerto Rico) and a pen recording oscillograph (Offner Dynograph Type R, Beckmann Instruments Inc., Schiller Park, Illinois, U.S.A.). The thermocouple in the testicular artery was removed, then, without attempting to staunch the escape of blood, immediately replaced with the needle previously in the femoral artery, and a recording of testicular arterial blood pressure was made. After removal of the needle from the artery, the bleeding was stopped, the spermatic cord was exposed to the inguinal ring and a needle containing a thermocouple inserted as close to the inguinal ring as possible. The colour and pressure of the blood which issued when the needle was removed indicated the type of vessel punctured. This was venous on all but one occasion. In some wallabies, all the measurements were repeated on the other testis. Only blood pressures were measured in the kangaroos.

There were no consistent differences between testicular temperature and the temperature of either testicular venous or testicular arterial blood; all were about $5^{\circ} \mathrm{G}$ cooler than rectal temperatures. The rectal-testicular differences were similar to the values of $4 \cdot 4 \pm 0.44^{\circ} \mathrm{C}$ ( \pm S.E. of mean, four observations) in conscious tammar wallabies and $3 \cdot 1 \pm 0 \cdot 39^{\circ} \mathrm{C}(4)$ in conscious brush-tailed

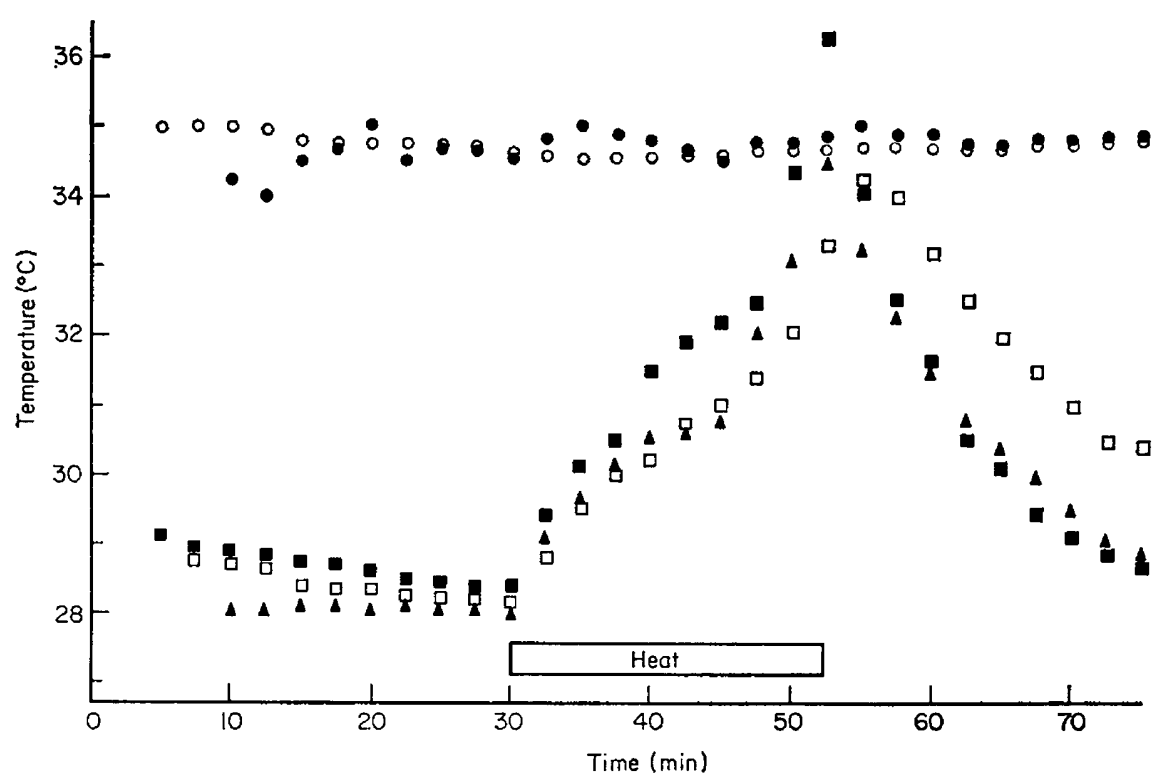

TEXT-FIG. 1. Temperature in the rectum (O), testis $(\square)$, a testicular artery $(\square)$ and a vein $(\Lambda)$ on the surface of the testis and an internal spermatic vein at the inguinal ring ( during heating of the testis of an anaesthetized tammar wallaby. 


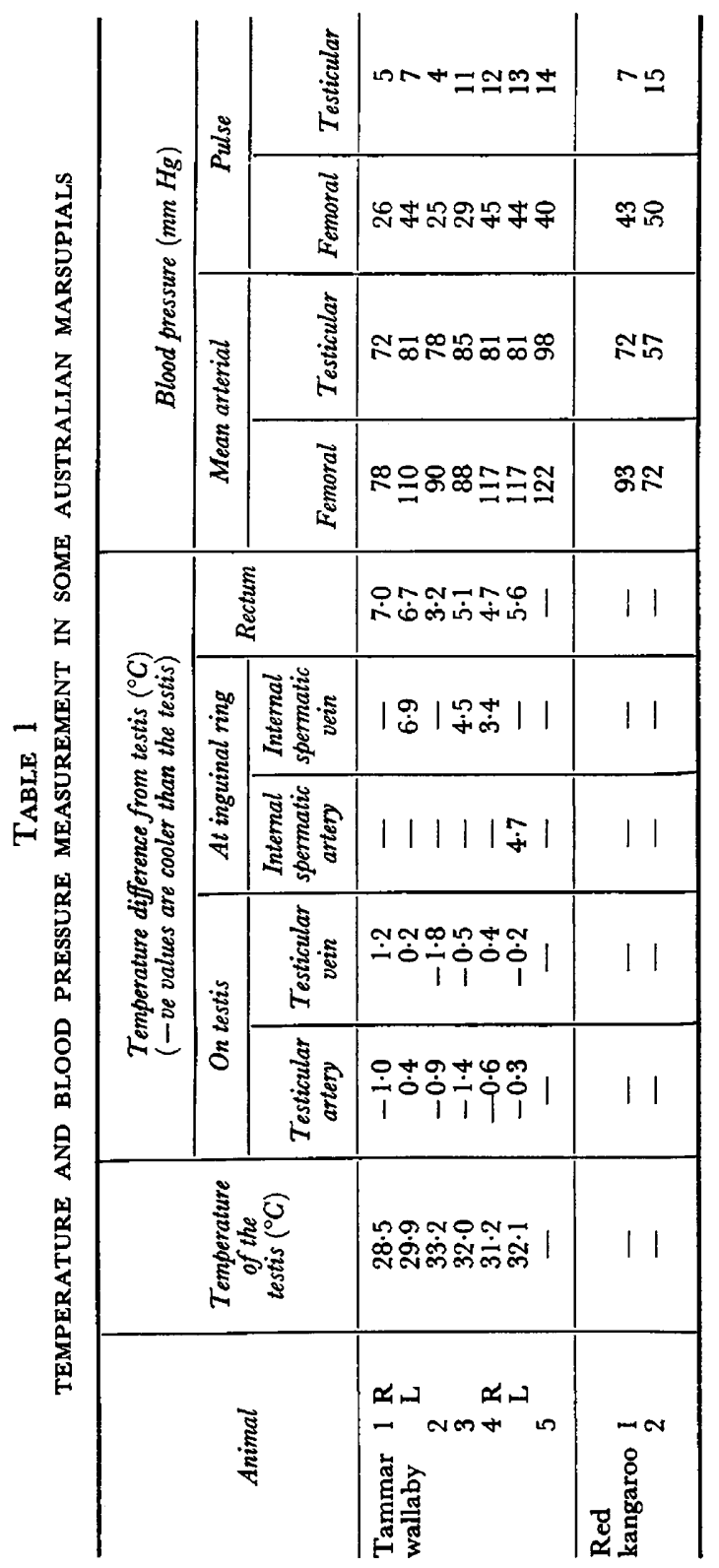



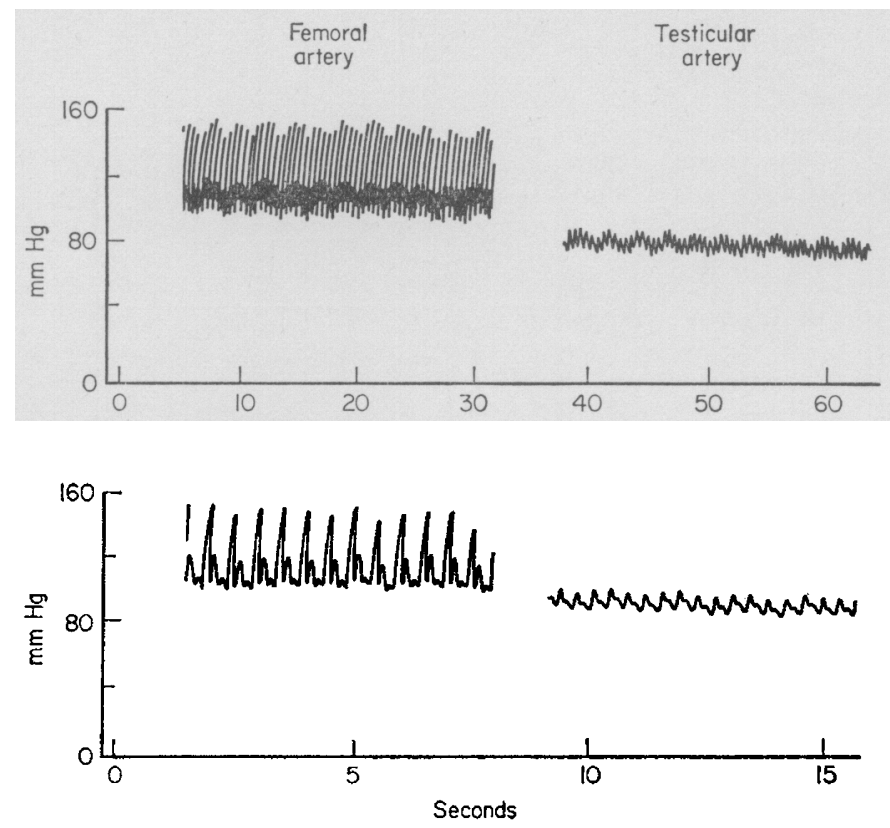

TEXT-FIG. 2. Recordings of blood pressure in the femoral artery at the same level as the testis and in the testicular artery on the surface of the testis of an anaesthetized tammar wallaby.

possums (Trichosurus vulpecula Kerr) measured in a room at about $22^{\circ}$ C. Blood temperatures in the spermatic veins and arteries at the inguinal ring were very similar to rectal temperature (Table 1). Testicular temperature was raised to rectal temperature over $20 \mathrm{~min}$ in one wallaby. The temperature of the testicular arterial and venous blood rose and, after heating, fell more quickly than testicular temperature, probably due to heat absorption and loss by the vessels themselves; there was no change in the temperature of the blood at the inguinal ring (Text-fig. 1).

The mean blood pressure in the testicular artery was only slightly less than in the femoral artery but a comparison of pulse pressures in these two arteries revealed a reduction of between 62 and $84 \%$ in the pulse pressure (Table 1, Text-fig. 2). As pulse pressure in the femoral artery reflects the size of pulse wave entering the spermatic artery, the multiple branches of this artery act to dampen the pulse wave. Thus, although the anatomy is different, the internal spermatic arteries of eutherian mammals and marsupials bring about the same effects of pre-cooling the arterial blood and pulse reduction. The eutherian arrangement seems slightly more effective in removing the pulse and both are effective systems for countercurrent heat exchange.

We are grateful to Professor G. M. Sharman, University of N.S.W., for his assistance in obtaining the wallabies from Kangaroo Island and to $\mathrm{Mr} \mathrm{W}$. E. Poole, CSIRO Division of Wildlife Research, for giving us the two kangaroos. 


\section{REFERENGES}

Barnett, G. H. \& Brazenor, C. W. (1958) The testicular rete mirabile of marsupials. Aust. J. Zool. 6, 27.

DAHL, E. V. \& Herrick, J. F. (1959) A vascular mechanism for maintaining testicular temperature by counter-current exchange. Surgery Gynec. Obstet. 108, 697.

Harrison, R. G. (1948) Vascular patterns in the testis, with particular reference to Macropus. Nature, Lond. 161, 339.

Harrison, R. G. (1949) The comparative anatomy of the blood-supply of the mammalian testis. Proc. zool. Soc. Lond. 119, 325.

Harrison, R. G. (1951) Application of microradiography: the testis. In: Microarteriography, p 89. Ed. A. E. Barclay. Blackwell Scientific Publications, Oxford.

Harrison, R. G. \& Weiner, J. S. (1949) Vascular patterns of the mammalian testis and their functional significance. F. exp. Biol. 26, 304.

Nagel, E. L., Morgane, P. J., McFarland, W. L. \& Galliano, R. E. (1968) Rete mirabile of dolphin: its pressure-damping effect on cerebral circulation. Science, N.X. 161, 898.

SETCHELI, B. P. (1969) Testicular blood supply, lymphatic drainage and secretion of fluid. In: The Testis. Eds. A. D. Johnson, W. R. Gomes and W. L. Vandemark. Academic Press, New York.

Wartes, G. M. H. (1969) Temperature regulation and the testis. In: The Testis. Eds. A. D. Johnson, W. R. Gomes and W. L. Vandemark. Academic Press, New York.

Wartes, G. M. H. \& Moule, G. R. (1960) Blood pressure in the internal spermatic artery of the ram. J. Reprod. Fert. 1, 223.

WATtes, G. M. H. \& MOULE, G. R. (1961) Relation of vascular heat exchange to temperature regulation in the testis of the ram. F. Reprod. Fert. 2, 213. 